\title{
Multi-Fetal Pregnancy Reduction Does Not Influence Perinatal Results in Twin Pregnancies
}

\author{
Simona Jirsova', Tonko Mardesic', Pavel Muller', Renata Huttelova', Jana Zvarova ${ }^{2}$ and Milan Jirkovsky ${ }^{2}$ \\ ' Institut Pronatal, Na Dlouhe mezi 4/I2, 147 00, Prague 4, Czech Republic \\ ${ }^{2}$ EuroMISE Statistical Center of Charles University and Academy of Sciences, Pod vodarenskou vezi 2, 182 07, Prague 8, Czech Republic
}

\begin{abstract}
The objective of this study was to compare perinatal results in multifetal pregnancies where the reduction to twins was performed with non-reduced twin pregnancies. Perinatal results in 99 sets of twins after transabdominal multifetal pregnancy reduction of triple and higher-order multiple pregnancies performed in a single center were compared with a control group consisting of 151 twin pregnancies conceived in the same time period after infertility treatment, which were not a result of reduction. The main outcome measures were length of pregnancies, weight of the newborns, percentage of miscarriages and the mode of the delivery were analyzed. No significant difference could be found at a $5 \%$ level of significance regarding the average duration of pregnancy or average weight of the twins. Fisher test on 5\% significance level did not ascertain any significant difference in the probability of miscarriage between the group with reduction $(5.26 \%)$ and the group without reduction (12.84\%). At a $5 \%$ level of statistical significance, no significant difference in probability of perinatal death of the fetus or delivery of a stillborn fetus was found. The percentage of cesarean sections did not differ significantly in both groups. The analysis of both groups demonstrated that reduction of multifetal pregnancies to twins may not influence perinatal results in comparison to twin pregnancies where reduction was not performed.
\end{abstract}

Due to recent development in assisted reproduction methods, especially using medical substances inducing multiple ovulation, the number of multifetal pregnancies has grown substantially. This complication, however, increases the incidence of maternal and perinatal mortality and morbidity (Petrikovsky \& Vintzileos, 1989). One of the possibilities (after all other preventive measures have failed) to reduce the occurrence of this negative phenomenon is multifetal pregnancy reduction (MFPR).

The multifetal pregnancy reduction was first described in 1978 (Aberg et al., 1978), for a twin pregnancy where Hurler's syndrome was proven for one of the fetuses. Reduction of the affected fetus was performed in the 24th week of pregnancy, the further course of the pregnancy was uneventful, and a healthy fetus was delivered. During the following 9 years several other cases of reduction were published, where the reduction was performed mostly for the reason of anomaly detected for one of the twins. The first case of reduction of multi-fetal pregnancy for the reason of more than two fetuses was published in 1986 (Kanhai et al., 1986). The first results referring to larger groups of multi-fetal pregnancies after reduction were published in 1988 by Berkowitz et al. and Evans et al. (1988). Since then, this method is one of the possibilities to address the negative effect of multi-fetal pregnancies on perinatal results.

\section{$\overline{\text { Materials and Methods }}$}

We analyzed perinatal results for women with twin pregnancies resulting after infertility treatment by assisted reproduction techniques in our unit during the period of time from January 1, 1996 to December 31, 1998. In the study group there were 99 twin pregnancies that originated as a result of reduction of triple and higher-order pregnancies. In 83 cases, the reduction was performed from the original number of 3 fetuses, in 5 cases from 4 fetuses and in 2 cases the original number of fetuses was 5 or more. We evaluated the length of pregnancy, weight of the newborns, percentage of miscarriages and the mode of delivery. These results were compared with the control group consisting of 151 twin pregnancies conceived after infertility treatment during the evaluated time period that did not undergo MFPR. In all pregnancies complete perinatal data were available for evaluation.

A patient is informed of the possibility of reduction as soon as possible after the multi-fetal pregnancy is detected, and acquainted, in detail, with possible risks and course of the procedure. Reduction of multi-fetal pregnancy is performed as an outpatient procedure, between the 10th and 11 th week of pregnancy, when the number of developing fetuses is usually final. Antibiotics (Netromycin $100 \mathrm{mg}$ in $100 \mathrm{ml} \mathrm{FR} \mathrm{1/1} \mathrm{infusion} \mathrm{and} \mathrm{Zinacef} 750 \mathrm{mg}$ in $100 \mathrm{ml}$ FR $1 / 1$ infusion) are used before and 4 hours after procedure. After common preparation, $1-2 \mathrm{ml}$ of KCL is applied from trans-abdominal approach intracardially, under ultrasound control, until asystolia. Rh-conflict prevention in Rh negative patients is given. For the next day, the patient is invited for a check-up ultrasonography and examination at our outpatient department. Further care of these patients takes

Address for correspondence: T Mardesic, Institut Pronatal, $\mathrm{Na}$ Dlouhe mezi 4/12, 147 00, Prague 4, Czech Republic. E-mail: pronatal@mbox.vol.cz 
place through our prenatal consulting center, or through a gynaecologist in the place of residence of the patient, while a check-up at our institute is recommended in the 28th 30 th week of pregnancy. Statistical evaluation was performed using linear regression, Wilcoxon two-sample test and Fisher test.

\section{Results}

We had two sets of data available for our study - mothers with twins after reduction of multi-fetal pregnancy and mothers with twins where the reduction was not performed (Table1). In both groups the information about the week and mode of delivery and weight of fetuses $A$ and $B$ was available.

\section{Average Length of Pregnancy}

The average length of pregnancy for the group of patients after reduction was $35.3 \pm 4.2$ weeks, and for the group without reduction $35.7 \pm 4.1$ weeks. At $5 \%$ level of significance we did not prove any differences between the groups in average length of pregnancy (Table2).

\section{Average Weight of Twins}

Average weight of the twins depends only on the week of termination of pregnancy. Thus, we may test the difference in weights in 2 ways:

a) testing of weight taking into account length of pregnancy, that is, with interpretation "if all the mothers had delivered in the same week".

b) testing of absolute weight, which does not take into account other circumstances (i.e., length of pregnancy).

Neither of these tests proved any differences between the groups as for the average weight of the twins, at 5\% significance level. The average weight for the group of patients after reduction was $2316 \pm 570 \mathrm{~g}$, and for the group without reduction $2406 \pm 503 \mathrm{~g}$ (Table2).

\section{Percentage of Miscarriages for Both Groups}

Fisher test at 5\% significance level did not ascertain any significant difference in probability of miscarriage (Table 3) between the group with reduction $(5.55 \%)$ and the group without reduction (14.72\%).

At $5 \%$ level of significance, there is no difference in the probability of occurrence of perinatal death of the fetus (1.10\% after MFPR vers $1.53 \%$ in control group) or delivery of a stillborn fetus $(2.17 \%$ after MFPR versus $0.38 \%$ in controls). It is, however, necessary to point out a very low frequency of occurrence of these phenomena in our group.
Table 2

Average Length of Pregnancy and Weight of Twins

\begin{tabular}{lccc}
\hline Group & With reduction & Without reduction & Statistics \\
\hline $\begin{array}{l}\text { Lengths of } \\
\text { pregnancy (weeks) }\end{array}$ & $35,3 \pm 4,2$ & $35,7 \pm 4,1$ & Not significant \\
$\begin{array}{l}\text { Average weight } \\
\text { of fetuses }(\mathrm{g})\end{array}$ & $2316 \pm 570$ & $2406 \pm 503$ & Not significant \\
\hline
\end{tabular}

\section{Table 3}

Percentage of Miscarriages for Both Groups

\begin{tabular}{lcccc}
\hline Abortion & \multicolumn{2}{c}{ With reduction } & \multicolumn{3}{c}{ Without reduction } \\
\hline YES & 5 & $(5.55 \%)$ & 19 & $(14.72 \%)$ \\
NO & 85 & $(94.45 \%)$ & 110 & $(85.28 \%)$ \\
Total & 90 & $(100.00 \%)$ & 129 & $(100.00 \%)$ \\
\hline
\end{tabular}

\section{Table 4}

Percentage of Cesarean Section

\begin{tabular}{lcccc}
\hline & \multicolumn{3}{c}{ Group with reduction } & Group without reduction \\
\hline $\begin{array}{l}\text { Percentage } \\
\text { of s.c. }\end{array}$ & 76 & $(84.44 \%)$ & 111 & $(87.24 \%)$ \\
$\begin{array}{l}\text { Percentage of } \\
\text { spontaneous }\end{array}$ & & & & \\
deliveries & 14 & $(15.56 \%)$ & 18 & $(12.76 \%)$ \\
Total & 90 & $(100 \%)$ & 129 & $(100 \%)$ \\
\hline
\end{tabular}

\section{Percentage of Caesarean Section}

The percentage of pregnancies terminated by cesarean section (Table 4) in the monitored groups did not differ significantly $(84.44 \%$ for the monitored group versus $87.24 \%$ for the group of non-reduced twin pregnancies).

\section{$\overline{\text { Discussion }}$}

There are 3 basic techniques of performing MFPR (6) - the transcervical, transvaginal and transabdominal approaches.

Trans-Cervical Aspiration. Under transabdominal ultrasonography control, a suction catheter is led through the cervix channel, and the gestational sack in the lowest location is aspired. This method is, however, being abandoned due to frequent occurrence of uncontrollable bleeding

\section{Table 1}

Analysis of Both Groups

\begin{tabular}{|c|c|c|c|c|c|}
\hline Type & $\begin{array}{l}\text { Total number of mothers } \\
\text { with known results }\end{array}$ & Mothers with "AB" & Mothers with "FM" & Mothers with "EX" & $\begin{array}{l}\text { Mothers with } \\
\text { complete data } \\
\text { without "AB", } \\
\text { "FM", "EX" }\end{array}$ \\
\hline With reduction & 99 & 5 & 3 & 1 & 90 \\
\hline Without reduction & 151 & 19 & 1 & 2 & 129 \\
\hline
\end{tabular}

Note: $\mathrm{AB}=$ abortion, $\mathrm{FM}=$ dead fetus, $\mathrm{EX}=$ death of a newborn after delivery 
resulting in termination of pregnancy, and high risk of infection (Berkowitz et al., 1988; Dechaud et al., 1998).

Trans-Vaginal Approach. Under vaginal sonographiy control a bioptic needle is guided into the thorax of the lowest fetus and KCL is injected.

Trans-Abdominal Technique. Currently the most frequently applied method using intra-thoracic application of KCL until asystolia of the fetus under transabdominal ultrasonography control.

A number of studies may be found in the literature which document negative effects of reduction on perinatal results of twin pregnancies (Alexander et al., 1995; Melgar et al., 1991; Silver et al., 1997). For example, Melgar et al. (1991) demonstrated this on a group of 14 twin pregnancies originated as a result of reduction of triple and quadruple pregnancies, by comparing them with 22 twin pregnancies where reduction was not performed. His study implies that twin pregnancies after reduction achieve significantly lower average length of pregnancy, thus lower delivery weights of newborns. Alexander et al. (1995) arrived at similar results, finding a higher percentage of premature deliveries on a group of 32 twin pregnancies after reduction in comparison with a group of 38 pregnancies where reduction was not performed. Both the above-mentioned studies, however, are dealing with rather small numbers of patients. Another similar paper by Silver (1997) compares a group of 18 twin pregnancies originated as a result of reduction of multi-fetal pregnancies with a group of 54 twin pregnancies conceived spontaneously and a group of 54 twin pregnancies after treatment for infertility. It should be pointed out, however, that the group of twin pregnancies after reduction included only pregnancies after reduction from 4-5 and even 6 fetus pregnancy, and, as indicated by many other studies, the higher the original number of fetuses, the worse are the perinatal results of pregnancies after reduction. This may well explain significantly worse results for the group being monitored.

In our group - rather extensive compared to previous ones - we did not observe any difference in the two groups. Our results are consistent with a number of other studies (Evans et al., 1988; Evans et al., 1996; Fasouliotis \& Schenker, 1997; Selam et al., 1999; Torok et al., 1998; Yaron et al., 1999). For example, a study by Torok et al. (1998) compares 441 monitored pregnancies after reduction with 136 pregnancies where reduction was not performed, and it proves that reduction of multi-fetal pregnancy is not related to intra-uterine growth retardation of fetus, nor to shorter length of pregnancy, unless the original number of fetuses is 5 or more. Another study supporting our conclusion is a study by Yaron et al. (1999), where they prove that reduction of a triple pregnancy to a twin one reduces the risk of prematurity, while perinatal results do not differ from results of originally twin pregnancies. Furthermore, extensive studies processing data from several centers confirm that perinatal results are not worsened by reduction of multi-fetal pregnancy (Fasouliotis \& Schenker, 1997). In 1997 a study by Fasouliotis et al. was published, analyzing the results of 1453 pregnancies after reduction, which had been published in the literature during the years
1993 - 1997. The study concluded that multifetal pregnancy reduction is a safe way to improve perinatal results.

Another issue often discussed is the most suitable time to perform reduction (Berkowitz et al., 1996). At our institute, we perform reduction of multi-fetal pregnancy in the last weeks of the first trimester, usually between the 9th and 12th week of pregnancy. The reason for this (except "technical" aspects in obese patients) is that in multi-fetal pregnancies, an early fetal resorption often occurs - a "vanishing twin" syndrome. Most such resorptions occur by the 10th week of pregnancy; therefore we consider the timing of reduction by the end of the last trimester suitable.

Although there were more abortions in twins without MFPR than after MFPR in our group, this difference was not statistically significant. There were also no long-term sequelae related to MFPR procedure alone. However, this is a subject of an ongoing long-term study.

\section{$\overline{\text { Conclusion }}$}

As shown by the analysis of both our groups, multifetal pregnancy reduction to twins seems not to worsen perinatal results in comparison with twin pregnancies where MFPR was not performed. We did not observe any difference in the length of pregnancy, average weights of fetuses, percentage of miscarriages or in the mode of the delivery. However, the prevention of iatrogenic causes of multiple pregnancies is a priority and moral line before any use of assisted reproductive techniques should be drawn. Physicians should adopt all possible measures designed to prevent the occurrence of multiple pregnancies.

Though the primary task remains to eliminate multifetal pregnancies as a result of treatment by assisted reproduction techniques, once such complications have occurred, reduction of multi-fetal pregnancies offers a possibility to reduce maternal and perinatal complications.

\section{References}

Petrikovsky, B. M., \& Vintzileos, A. M. (1989). Management and outcome of multiple pregnancy of high fetal order: Literature review. Obstetrical and Gynecological Survey, 44, 578-584.

Aberg, A., Mitelman, F., Cantz, M., \& Gehler, J. (1978). Cardiac puncture of fetus with Hurler's desease avoiding abortion of unaffected co-twin. Lancet, 2, 990-991.

Kanhai, H. H., van Russel, E. J. C., \& Meerman, R. J. (1986). Selective termination in quintuplet pregnancy during first semester. Lancet, 2, 1447.

Berkowitz, R. L., Lynch, L., Chitkara, U., Wilkins, I. A., Mehalek, K. E., \& Alvarez, E. (1988). Selective reduction of multifetal pregnancies in the first trimester. New England Journal of Medicine, 318, 1043- 1047.

Evans, M. I., Fletcher, J. C., Zador, I. E., Newton, B. W., Quigg, M. H., \& Struyck, C. D. (1988). Selective first trimester termination in octuplet and quadruplet pregnancies: Clinical and ethical issues. Obstetrics and Gynecology, 71, 289-296.

Hammond, K. R. (1998). Multifetal pregnancy reduction. Journal of Obstetric, Gynecologic, and Neonatal Nursing, 27, 338-343.

Dechaud, H., Picot, M. C., Hedon, B., \& Boulot, P. (1998). First trimester multifetal pregnancy reduction: Evaluation of 
technical aspects and risks from 2756 cases in literature. Fetal Diagnosis and Therapy, 13, 261-265.

Alexander, J. M., Hammond, K. R., \& Steinkampf, M. P. (1995). Multifetal reduction of high-order multiple pregnancy: Comparison of obstetrical outcome with spontaneous twin gestations. Fertility and Sterility, 64, 1201-1203.

Melgar, C. A., Rosenfeld, D. L., Rawlinson, K., \& Greeberg, M. (1991). Perinatal outcome after multifetal reduction to twins compared with nonreduced multiple gestations. Obstetrics and Gynecology, 78, 763-766.

Silver, R. K., Helfand, B. T., Russell, T. L., Ragin, A., \& Sholl, J. S. (1997). Multifetal reduction increases the risk of preterm delivery and fetal growth restriction in twins: A case-control study. Fertility and Sterility, 67, 30-33.

Evans, M. I., Dommerques, M., Wapner, R. J., Godberg, J. D., Lynch, L., Zador IE et al. (1996). International, collaborative experience of 1789 patients having multifetal pregnancy reduction: A plateauing of risks and outcomes. Journal of the Society for Gynecological Investigation, 3, 23-26.

Fasouliotis, S. J., \& Schenker, J. G. (1997). Multifetal pregnancy reduction: A review of the world results for the period
1993-1996. European Journal of Obstetrics \& Gynecology and Reproductive Biology, 75, 183-190.

Selam, B., Lembet, A., Stone, J., Lapinski, R., \& Berkowitz, R. L. (1999). Pregnancy complications and neonatal outcomes in multifetal pregnancies reduced to twins compared with nonreduced twin pregnancies. American Journal of Perinatology, 16, $65-71$.

Torok, O., Lapinski, R., Salafia, C. M., Bernasko, J., \& Berkowitz, R. L. (1998). Multifetal pregnancy reduction is not associated with an increased risk of intrauterine growth restriction, except for very high-order multiples. American Journal of Obstetrics and Gynecology, 179, 221-225.

Yaron, Y., Bryant-Greenwood, P. K., Dave, N., Moldenhauer, J. S., Kramer, R. L., Johnson, M. P., et al. (1999). Multifetal pregnancy reduction of triplets to twins: Comparison nonreduced triplets and twins. American Journal of Obstetrics and Gynecology, 180, 1268-1271.

Berkowitz, R. L., Lynch, L., Stone, J., \& Alvarez, M. (1996). The current status of multifetal pregnancy reduction. American Journal of Obstetrics and Gynecology, 74, 1265-1272. 